\title{
Why Japan's professors fear evaluation
}

Sir - You pointed out the necessity of external review of Japanese universities (Nature 397, 371; 1999). It is true that external evaluation works efficiently if universities have equal opportunities in research — that is, if the 'losers' after evaluation have a chance to become 'winners' one day. But, because of the hierarchy among Japanese universities, the losers will have no such chance. This explains why professors in reputable universities are scared of external evaluation.

Table 1 shows a comparison of the two leading national universities, the University of Tokyo and Kyoto University, with two typical local national universities, Niigata University and Tottori University; the best two private universities, Waseda University and Keio University; and the best private science university, the Science University of Tokyo. Waseda and Keio have the best reputation in literature, economics and politics. There are remarkable differences between the scientific grants obtained by the best national universities and the rest.

But lower grants do not necessarily imply lower scientific quality of faculty members. They are more likely to reflect a lack of time for research, because of heavy teaching duties, especially in private universities. And note the differences in the ratios of students to faculty members. As a result of the heavy

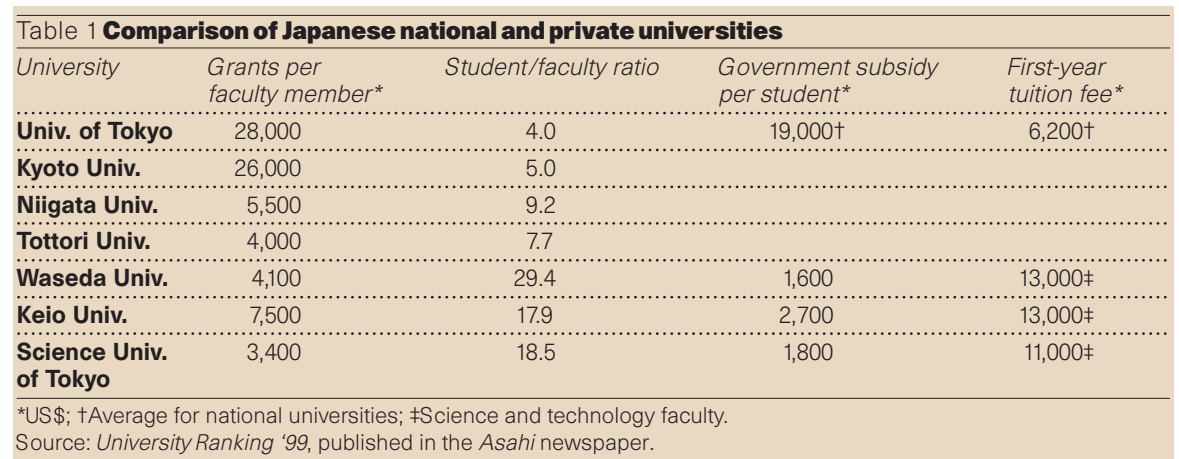

teaching load, good scientists at private or local national universities rarely publish important papers.

The income of private universities is almost completely dependent on tuition fees from students. Faculty members are not allowed to draw their salaries from scientific grants from the Ministry of Education, Science, Sports and Culture (Monbusho), and the private universities are not allowed to get overheads from the grants. National universities, on the other hand, are subsidized by the government without any assessment. Private universities receive only about one tenth of the subsidy per student that is given to national universities.

Given this unfair situation, who can expect fair competition in research? The situation is similar to the issue of the trade imbalance between Japan and other countries. Although Japanese markets are officially declared open to foreign companies, they cannot gain 'fair' access. Similarly, it is impossible for private universities to compete with national universities in research.

This problem seems to be intrinsic to Japanese society. Recently, the Council on University Education, an advisory body to Monbusho, published a report proposing a plan to stimulate competition among universities. Amazingly, however, there is not a word in the report about problems caused by the hierarchy among universities. Mitsuo Tagaya School of Life Science,

Tokyo University of Pharmacy and Life Science, Horinouchi, Hachioji 192-0392, Japan

\section{SomePhDs are more equal than others}

Sir - One important aim of the European Union (EU) is to allow the free circulation of people among the different countries. In spite of this, countries such as Portugal demand that a $\mathrm{PhD}$ awarded abroad must be 'recognized' in Portugal before a researcher can have a university job.

The quickest way of gaining this 'recognition' is to 'register' the $\mathrm{PhD}$, a process that involves the submission of the diploma, a copy of the thesis and a payment of up to 25,000 escudos, about US\$130, to a Portuguese university. Usually, $\mathrm{PhD}$ status is granted after 10 days. A more lengthy process known as 'equivalence' involves the re-evaluation of the thesis by a panel of Portuguese professors, as if the judgement of the original jury was not to be trusted.

Although everyone assumes these to be bureaucratic formalities, they do allow for the possibility of revoking a degree awarded by another EU university, and indeed the University of Lisbon has recently chosen to reject the $\mathrm{PhD}$ that I obtained at the

NATURE |VOL 398 | 29 APRIL 1999 | www.nature.com
Technical University of Denmark in 1988. Are we really free to move between the universities of all EU countries?

Leonor Cruzeiro-Hansson

Mathematics Department, Heriot-Watt University, Edinburgh EH14 4AS, UK

\section{Name and shame the scientific fraudsters}

Sir - With regard to the recent coverage of fraud in science ${ }^{1}$, I would like to suggest some remedial actions to counter fraud and malfeasance in British universities.

I am not alone in my anger and contempt for universities that abuse scientists and others ${ }^{2,3}$. But it is difficult to obtain legal redress against a British university administration. A university with a royal charter has special status in common law that renders it invulnerable to prosecution in a county court.

An excellent survey of grievance procedures, by Don Staniford et al. ${ }^{4}$ of the National Postgraduate Committee, illustrates the problems clearly. The present system allows for complaints to be investigated by a 'university visitor', appointed by the Privy Council. But trying to get the Privy Council to act on your behalf is like getting a live eel into a jar of Swarfega.

The cause of academic fraud and malfeasance is greed and conceit with relative impunity. My suggested remedies are, first, to end the chartered status of British universities. Second, to register all research students directly with their universities and not to their supervisors. Third, for science journals to fund a task force to maintain a database of all suspected and proven agents of fraud and malpractice, and to investigate and collect relevant information. The task force would act as an advice bureau for honest scientists, with the power of naming and shaming all proven cases in the journals. Fourth, for all research funding bodies to check with the task force before allocating grants.

James McComb

12 Russell House, Cross Lane, Newport,

Isle of Wight PO30 2JJ, UK

e-mail:jimmccomb@aol.com

1. Abbott, A. et al. Nature 398, 13-17 (1999).

2. McComb. J, Nature 387, 448 (1997).

3. Anon. Nature 393, 407 (1998).

4. Staniford, D. http://www.npc.org.uk/ 